\title{
The effect of hydroalcoholic extract of Urtica dioica on morphine withdrawal signs in male mice
}

\author{
Assad Assadi $^{1^{*} \mathbb{D}}$, Saeid Abbasi-Maleki ${ }^{2}$ \\ ${ }^{1}$ Department of Veterinary Medicine, Miyaneh Branch, Islamic Azad University, Miyaneh, Iran \\ ${ }^{2}$ Department of Pharmacology \& Toxicology, Urmia Branch, Islamic Azad University, Urmia, Iran
}

\section{A R T I C L E I N F O}

\section{Article Type:}

Short Communication

\section{Article History:}

Received: 13 February 2018

Accepted: 2 September 2018

\section{Keywords:}

Urtica dioica

Morphine

Naloxone

Withdrawal syndrome $\mathrm{LD}_{50}$

\begin{abstract}
A B S T R A C T
Introduction: Previous studies have shown the analgesic, anticonvulsant, spasmolytic, and anti-inflammatory effects of Urtica dioica (UD). In the present study the effects of hydroalcoholic extract of UD on morphine withdrawal signs were investigated. Acute toxicity $\left(\mathrm{LD}_{50}\right)$ of the extract was also assessed.

Methods: In an experimental study, 48 male NMRI mice were randomly divided into 6 groups of 8 each, consisting of control $(10 \mathrm{~mL} / \mathrm{kg})$, clonidine $(3.5 \mathrm{mg} / \mathrm{kg})$, and different doses of UD extract $(25,50,100$ and $200 \mathrm{mg} / \mathrm{kg})$. Morphine dependency was induced by administration of different doses of morphine $(50,50,75$, and $50 \mathrm{mg} / \mathrm{kg}$ ) within a four-day schedule (1st- $4 \mathrm{th}$ day, respectively). On the last day, after administration of a single dose of morphine, naloxone $(5 \mathrm{mg} / \mathrm{kg})$ was injected and the withdrawal signs were recorded within 30 minutes. To assess acute toxicity (LD50), 12 extra rats were used and toxic effects of different doses of the extract were evaluated by Lorke's method.

Results: All doses of the UD extract, compared to control group, significantly decreased the number of jumping, grooming, teeth chattering, rearing, wet dog shakes, diarrhea, writing and climbing. In addition, the $\mathrm{LD}_{50}$ of the extract was $2.9 \mathrm{~g} / \mathrm{kg}$.

Conclusion: UD extract could decrease the morphine withdrawal signs and might be beneficial in addicted patients. However, further studies are needed to clarify the exact mechanism of its action.
\end{abstract}

Implication for health policy/practice/research/medical education:

The present study findings showed that Urtica dioica extract could decrease the morphine withdrawal signs and might be beneficial in addicted patients.

Please cite this paper as: Assadi A, Abbasi-Maleki S. The effect of hydroalcoholic extract of Urtica dioica on morphine withdrawal signs in male mice. J Herbmed Pharmacol. 2018;7(4):220-224. doi: 10.15171/jhp.2018.34.

\section{Introduction}

Physical dependence is one of the unwanted and longterm effects of opioid use (including morphine) that is characterized by signs of morphine withdrawal. These signs are characterized by various hateful behaviors and a number of physiological signs in many species. The withdrawal syndrome is clearly present particularly after cessation of morphine use or after the administration of opioid antagonists in addicted subjects $(1,2)$.

Previous studies have suggested that various systems, including dopaminergic, noradrenergic, and GABAergic systems are involved in the process of development of these signs. However, studies on the impact of other effective systems on the development of morphine withdrawal signs are still ongoing (3-8).
Currently, various chemical drugs such as methadone are routinely used to control and treat some of the symptoms in opioid addicts. However, many patients do not respond to this method and even experience some side effects $(9,10)$. Accordingly, the use of drugs with low-side effects, especially herbal drugs, is one of the research priorities across the globe. The beneficial effects of certain plants such as Carthamus tinctorius L., Rosa damascena, Avena sativa L., Ferula gummosa Boiss, Salvia leriifolia, Passiflora incarnata L., Origanum majorana L., and Pimpinella anisum to reduce the morphine withdrawal signs have previously been demonstrated (11-19).

Urtica dioica (UD) is an herbaceous, perennial plant with an erect stem. reaching a height of up to one meter. This plant has a creeping root that is constantly 
growing. Studies have shown that flavonoids such as quercetin and kaempferol exist in the UD structure. This plant also contains vitamins $\mathrm{C}$ and $\mathrm{K}$, and $\mathrm{B}$ vitamins. Previous studies have shown analgesic, anticonvulsant, antispasmodic, sexual enhancer, and anti-inflammatory effects of UD (20). Considering this background and the lack of a study in this regard, this study was first to investigate the effect of hydroalcoholic UD extract on the morphine withdrawal signs in male mice. Acute toxicity $\left(\mathrm{LD}_{50}\right)$ of the extract was also assessed.

\section{Materials and Methods}

\section{Animals}

In this experimental study, a total 60 (48 mice for morphine dependence study and 12 mice for acute toxicity study) male NMRI mice (obtained from the Animal House of Urmia University of Medical Sciences, Iran) weighing 20-30 g were used. Animals were kept in separate cages at $23 \pm 2^{\circ} \mathrm{C}$ and a 12 -hour light/12-hour dark cycle. During this period, commercially available water and food (in the form of a commercial pellet) were provided to them, and each animal was used only once. All experiments were carried out during the light period from 8:00 to 12:00.

\section{Drugs and extracts}

In the present study, morphine sulfate (Temad Co., Iran), naloxone hydrochloride (Tolidaru, Iran) and clonidine hydrochloride (Tolidaru, Iran) were used. The extract of UD was purchased from Giah Essence Pharmaceutical Co., (Gorgan, Iran, Bath no.: 005). In this study, all drugs and even the extract were administered intraperitoneally at constant volume of $10 \mathrm{~mL} / \mathrm{kg}$. All drugs were dissolved in normal saline $(0.9 \%)$.

\section{Morphine dependence}

Morphine was injected for four consecutive days as follows: From the first to third day, the mice were administered with, respectively, 50, 50, and $75 \mathrm{mg} / \mathrm{kg}$ doses of morphine according to a regular program at 8:00, 11:00, and 15:00, daily. On day 4 , mice received only a single dose $(50 \mathrm{mg} /$ $\mathrm{kg}$ ) of morphine at 8:00, and 2 hours later, naloxone at 5 $\mathrm{mg} / \mathrm{kg}$ was injected $(11,17,19)$.

Animals were completely randomly assigned to 6 groups of 8 each, as follows: 1) Negative control group: The mice in this group received normal saline $(10 \mathrm{mg} / \mathrm{kg}$, i.p. $) 30$ minutes prior to receiving the last dose of morphine (50 $\mathrm{mg} / \mathrm{kg}$ ) on the fourth day and 30 minutes later, received naloxone $(5 \mathrm{mg} / \mathrm{kg})$, and then the signs were recorded.

2) Standard drug (clonidine) group: The mice in this group received clonidine $(3.5 \mathrm{mg} / \mathrm{kg}$, i.p.) 30 minutes prior to receiving the last dose of morphine $(50 \mathrm{mg} / \mathrm{kg})$ on the fourth day and 30 minutes later, received naloxone (5 $\mathrm{mg} / \mathrm{kg}$ ), and then the signs were recorded.

3) Groups treated with different doses of hydroalcoholic extract of UD: The mice in these groups received UD extract at different doses $(25,50,100$, and $200 \mathrm{mg} / \mathrm{kg}) 30$ minutes prior to receiving the last dose of morphine (50 $\mathrm{mg} / \mathrm{kg}$ ) on the fourth day and 30 minutes later, received naloxone $(5 \mathrm{mg} / \mathrm{kg})$, and then the signs were recorded $(11,17,19)$. In this study, the administration schedule of the drugs and extracts and the doses were selected with reference to the previous studies $(11,17,19,21)$.

After injection of the extract or drugs, the mice were quickly transferred into a cylindrical glass $25 \mathrm{~cm}$ in diameter and $40 \mathrm{~cm}$ in height. The morphine withdrawal signs including the number of jumping, behaviors such as grooming, climbing, rearing, teeth chattering, wet dog shakes, diarrhea, and writing were recorded for 30 minutes $(17,19)$. In this study, all signs were recorded by a single person who was blind to the grouping of the mice.

Acute toxicity test $\left(\mathrm{LD}_{50}\right)$

We used the Lorke's method to determine the extract acute toxicity $\left(\mathrm{LD}_{50}\right)(21)$. This method consists of two separate phases. In the first phase, nine animals in three groups of three each received different doses of UD extract $(10,100$ and $1000 \mathrm{mg} / \mathrm{kg}$, i.p.). The animals were monitored for any signs of toxicity and possible death during 24 hours. In the second phase, 3 animals in each group received different higher doses (1600, 2900 and $5000 \mathrm{mg} / \mathrm{kg}$, i.p.) of UD extract. Similar to the first phase, the mice were monitored for any signs of toxicity and possible deaths during 24 hours. After the two phases, the $\mathrm{LD}_{50}$ was calculated by the following formula:

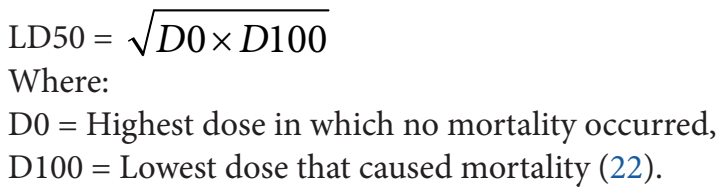

Statistical analysis

In this study, quantitative data (number of jumps) were expressed as mean \pm standard error of mean (SEM) and qualitative data (grooming, teeth chattering, writing, diarrhea, climbing, rearing, and wet dog shakes) as 25\%-median-75\%. For analysis of quantitative data, oneway analysis of variance (ANOVA) and then Tukey's test were used, and for analysis of the qualitative data, the Mann-Whitney $U$ test was used. $P<0.05$ was considered significance level. The SPSS version 19 was used to analyze the data.

\section{Results}

The effects of different doses of extract on morphine withdrawal signs

All doses of UD extract reduced the number of jumping $(P<0.001)$ when compared to control group in morphine-dependent mice (Figure 1). All 3 doses of the extract reduced grooming, teeth chattering, rearing, wet dog shakes, and diarrhea. But, all doses of the extract 


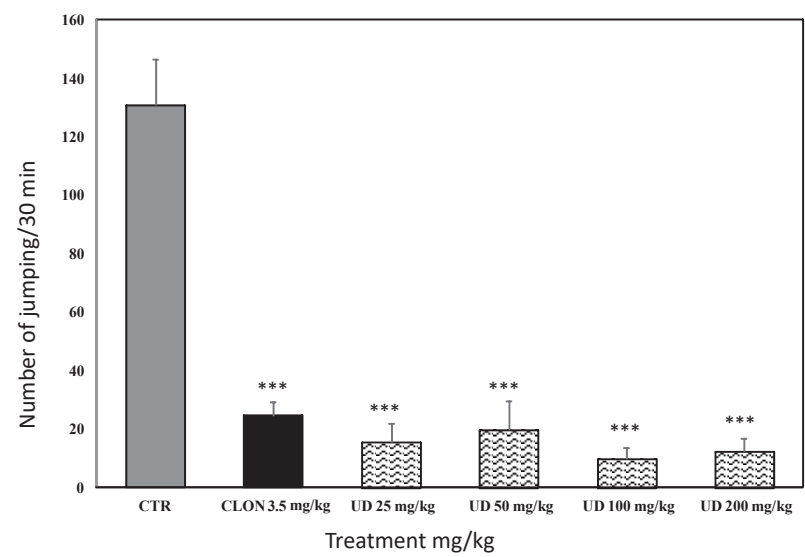

Figure 1. Effect of different doses of hydroalcoholic extract of Urtica dioica (UD) and clonidine on the number of naloxone-induced jumping in morphine dependent mice. The results were expressed as mean \pm standard error of measurement for eight mice. ${ }^{* * *} P<0.001$ compared to control group. CTR: Control; CLON: Clonidine.

decreased the writing and climbing behaviors $(P<0.05)$. In addition, clonidine as a reference drug reduced the number of jumping $(P<0.001)$, grooming $(P<0.01)$, teeth chattering $(P<0.05)$, climbing $(P<0.05)$, writhing $(P<0.01)$ and diarrhea $(P<0.01)$. But, clonidine could not reduce the rearing and wet dog shake behaviors $(P>0.05)$.

\section{Acute toxicity test}

No mortality was observed in any doses of extract except for the highest dose $(5000 \mathrm{mg} / \mathrm{kg})$. On the other hand, based on our findings the $\mathrm{LD}_{50}$ of UD extract was $2.9 \mathrm{~g} / \mathrm{kg}$. Hence, the administration of any doses less than $2900 \mathrm{mg} /$ $\mathrm{kg}$ was safe in mice. Furthermore, some signs of toxicity including numbness, diarrhea and ataxia were observed with $2900 \mathrm{mg} / \mathrm{kg}$ of the extract in mice (Table 1).

\section{Discussion}

In this study, the effect of hydroalcoholic extract of UD on the morphine withdrawal signs in morphine-dependent mice was investigated. Consistent with the previous studies $(17,19)$, the 3 -day morphine administration caused a physical dependence and, following the administration of naloxone, morphine withdrawal signs were observed. The results showed that pretreatment with different doses of UD extract reduced the number of jumping in morphinedependent mice. However, all four doses of UD extract significantly decreased the number of jumping more markedly than the standard drug clonidine (one of the $\alpha_{2}$ adrenergic drugs). As a standard drug; clonidine also decreased the number of jumping in morphine dependent mice. Clonidine is used to reduce the morphine withdrawal signs in humans and animals (23). These results are in agreement with the results of other studies $(24,25)$.

The number of jumping is one of the most important signs to determination the severity of morphine withdrawal signs (2). Previous studies have reported that serotonergic, cholinergic, and GABAergic systems are involved in the number of jumping caused by morphine withdrawal syndrome (3-8). In this regard, it has been shown that the serotonergic and cholinergic systems increase the number of jumping and the GABAergic system reduces the number of jumping in morphine dependent mice (26). In this regard, in agreement with our findings, previous studies have also highlighted the number of jumping (the most important symptom of morphine withdrawal) as an important behavior to study morphine tolerance or dependence. In other words, various extracts or essential oils reduce the number of jumping in morphinedependent mice (9-17).

Among other important morphine withdrawal signs, diarrhea can be mentioned. According to previous studies, the cholinergic system is involved in development of diarrhea (27). The results showed that all three doses of the extract and clonidine reduced diarrhea in morphine dependent mice. In addition to diarrhea, other signs, such as grooming, teeth chattering, rearing, wet dog shakes, writing, and climbing were reduced by the extract.

Considering the findings of this study, the strengths point of the study include the determination of the effect of hydroalcoholic UD extract in reducing the signs of morphine withdrawal syndrome and a limitation of the study is lack of determining the exact mechanism of its action.

Table 1. Effect of different doses of hydroalcoholic extract of Urtica dioica (UD) on morphine withdrawal signs

\begin{tabular}{|c|c|c|c|c|c|c|c|}
\hline Parameter/Group & Grooming & $\begin{array}{l}\text { Teeth } \\
\text { chattering }\end{array}$ & Climbing & Rearing & $\begin{array}{l}\text { Wet dog } \\
\text { shakes }\end{array}$ & Writing & Diarrhea \\
\hline Negative control (normal saline), $10 \mathrm{~mL} / \mathrm{kg}$ & $(3-2) \pm 2.5$ & $(3-1) \pm 2$ & $(3-1) \pm 2$ & $(3-1) \pm 2.5$ & $(2-1) \pm 1.5$ & $(3-2) \pm 2$ & $(3-2) \pm 2.5$ \\
\hline Positive control (clonidine), $3.5 \mathrm{mg} / \mathrm{kg}$ & $(1-0) \pm 1 * *$ & $(1-0) \pm 1^{*}$ & $(1-1) \pm 1^{*}$ & $(1-1) \pm 1$ & $(1-1) \pm 1$ & $(0-0) \pm 0 * *$ & $(1-0) \pm 0.5^{* *}$ \\
\hline UD $25 \mathrm{mg} / \mathrm{kg}$ & $(2-1) \pm 2$ & $(3-1) \pm 1$ & $(1-0) \pm 1^{*}$ & $(1-1) \pm 1$ & $(1-1) \pm 1$ & $(0-0) \pm 0 * *$ & $(3-1) \pm 3$ \\
\hline UD $50 \mathrm{mg} / \mathrm{kg}$ & $(2-1) \pm 1^{*}$ & $(1-1) \pm 1^{*}$ & $(1-1) \pm 1^{*}$ & $(1-1) \pm 1^{*}$ & $(1-0) \pm 0 *$ & $(1-0) \pm 0 * *$ & $(2-0) \pm 1^{*}$ \\
\hline UD $100 \mathrm{mg} / \mathrm{kg}$ & $(2-1) \pm 1^{*}$ & $(1-0) \pm 1 *$ & $(1-0) \pm 1^{*}$ & $(1-1) \pm 1^{*}$ & $(1-0) \pm 0^{*}$ & $(00-0) \pm 0 * *$ & $(1-0) \pm 1 * *$ \\
\hline UD 200 mg/kg & $(1-0) \pm 1 * *$ & $(1-0) \pm 1^{*}$ & $(1-0) \pm 1 *$ & $(1-1) \pm 1^{*}$ & $((0-0) \pm 0 *$ & $(00-0) \pm 0 * *$ & $(1-0) \pm 0 * *$ \\
\hline
\end{tabular}

In this study, qualitative data were expressed as 25\%-median-75\%, and for data analysis, Mann-Whitney U test was used.

${ }^{*} P<0.05 ;{ }^{*} P<0.01$, compared to control group. CTR: Control; CLON: Clonidine. 
Therefore, the UD components are responsible for its effects on reduction in the morphine withdrawal signs. In this regard, the phytochemical investigations have shown that in this plant there are numerous components such as fatty acids (e.g., a-linolenic acid), carotenoids (e.g., lutein isomers, beta-carotene isomers, and lycopene isomers), phenols (e.g., ferulic acid, gallic acid, and synergic acid), flavonoids (e.g., catechin and epicatechin) and other components including neoxetine and violaxanthin (26). However, studies have suggested that phenolic and flavonoid components in plants, by inhibiting the cholinergic system, may lead to inhibition of cholinesterase activity and subsequently reduction in the signs of morphine withdrawal syndrome (27). Meanwhile, ursolic acid and quercetin are two of the most important components of UD extract (28). In a similar study, Naidu et al. reported that quercetin induced the relapse of morphine tolerance and dependence. Quercetin causes reduction in the frequency of naloxone-induced jumping in morphine dependent mice (29). In addition, studies have reported that quercetin may reduce the naloxone-induced abdominal contractions through the mechanism of inhibiting the activity of nitric oxide synthase (30). In a similar study, flavonoids in plants (including quercetin) have reduced some of the morphine withdrawal signs, including abdominal contractions, diarrhea, teeth, number of jumps. This links the effects of flavonoids to their effects on the GABAergic system $(31,32)$. In addition to the quercetin, ursolic acid has shown different pharmacological effects in rodents including neuroprotective, antidepressant-like effect, antinociceptive and anxiolytic effects (33-35). On the other hand, Taviano et al demonstrated that ursolic acid isolated from Nepta sibthorpii inhibited the acetic acidinduced abdominal constriction. They also observed that naloxone could reverse the antinociceptive effects of ursolic acid in hot plate test. Hence, the antinociceptive effects of ursolic acid partly mediated by modulation of opioidergic system (36). Therefore, it may be opioidergic system that is involved in the alleviating effects of UD on morphine withdrawal signs.

Besides that, acute toxicity test demonstrated that the $\mathrm{LD}_{50}$ of UD extract was $2.9 \mathrm{~g} / \mathrm{kg}$. Hence, the administration of any doses less than $2900 \mathrm{mg} / \mathrm{kg}$ was safe in mice. On the other hand, the $\mathrm{LD}_{50}$ of $5000 \mathrm{mg} / \mathrm{kg}$ or higher in animal's should be considered to be practically harmless.

However, the use of various antagonists and the study of the effect of each of the active ingredients of UD on morphine withdrawal signs are suggested to determine the exact mechanism action of the hydroalcoholic extract of UD.

\section{Conclusion}

In conclusion, our results firstly demonstrate that the Urtica dioica extract could decrease the morphine withdrawal signs and might be beneficial in addicted patients. However, further studies are needed to clarify the exact mechanism of its action.

\section{Acknowledgements}

This paper was derived from a research project (no.: 14991) confirmed in Miyaneh Branch, Islamic Azad University in 2016. The authors of this paper gratefully thank the Research Deputy of this university for is support and the Giah Essence Pharmaceutical Co. (Gorgan, Iran) for preparing the UD extract.

\section{Author's contributions}

AA and SAM had an equal role in conceiving the study, designing the study, data analysis and preparation of the manuscript. All authors read and approved the final manuscript.

\section{Conflict of interests}

The authors declare no conflict of interest.

\section{Ethical considerations}

In the present study, all experiments were carried out in accordance with the Guide and Use of Laboratory Animals and the Declaration of Urmia University of Medical Sciences as well as the guidelines of National Institutes of Health Guide for the Care and Use of Laboratory Animals (NIH Publications No. 8023, revised 1978).

\section{Funding/Support}

This research was funded by the authors themselves.

\section{References}

1. Babhadiashar N, Vaseghi G, Rafieian-Kopaei M, Andalib S, Eshraghi A, Masoudian N. Neural mechanisms underlying morphine withdrawal in addicted patients: a review. Rev Clin Med. 2015;2(3):151-7. doi: 10.17463/rcm.2015.03.010.

2. el-Kadi AO, Sharif SI. The influence of various experimental conditions on the expression of naloxoneinduced withdrawal symptoms in mice. Gen Pharmacol. 1994;25(7):1505-10.

3. Lelevich SV, Lelevich VV, Novokshonov AA. Neurotransmitter mechanisms of morphine withdrawal syndrome. Bull Exp Biol Med. 2009;148(2):184-7.

4. Airio J, Ahtee L. The involvement of noradrenergic transmission in the morphine-induced locomotor hyperactivity in mice withdrawn from repeated morphine treatment. Br J Pharmacol. 1999;126(7):1609-19. doi: 10.1038/sj.bjp.0702485.

5. Ji D, Sui ZY, Ma YY, Luo F, Cui CL, Han JS. NMDA receptor in nucleus accumbens is implicated in morphine withdrawal in rats. Neurochem Res. 2004;29(11):2113-20.

6. Riahi E, Mirzaii-Dizgah I, Karimian SM, Sadeghipour HR, Dehpour AR. Attenuation of morphine withdrawal signs by a GABAB receptor agonist in the locus coeruleus of rats. Behav Brain Res. 2009;196(1):11-4. doi: 10.1016/j. bbr.2008.06.020. 
7. Herman BH, Vocci F, Bridge P. The effects of NMDA receptor antagonists and nitric oxide synthase inhibitors on opioid tolerance and withdrawal. Medication development issues for opiate addiction. Neuropsychopharmacology. 1995;13(4):269-93. doi: 10.1016/0893-133x(95)00140-9.

8. Abbasi Maleki S, Mosavi SZ, Rahbari Farzoo M, Khayatnouri MH. Evaluation of the effect of citalopram on morphinewithdrawal signs in male mice. J Rafsanjan Univ Med Sci. 2012;11(5):427-36.

9. Inturrisi CE. Pharmacology of methadone and its isomers. Minerva Anestesiol. 2005;71(7-8):435-7.

10. Pierce TL, Hope W, Raper C. The induction and quantitation of methadone dependence in the rat. J Pharmacol Toxicol Methods. 1996;36(3):137-46.

11. Abbasi Maleki S. Effect of ethanolic extract of Safflower on naloxone-induced morphine withdrawal signs in mice. Adv Herb Med. 2015;1(4):9-15.

12. Bhargava HN. Diversity of agents that modify opioid tolerance, physical dependence, abstinence syndrome, and self-administrative behavior. Pharmacol Rev. 1994;46(3):293-324.

13. Akhondzadeh S, Kashani L, Mobaseri M, Hosseini SH, Nikzad S, Khani M. Passionflower in the treatment of opiates withdrawal: a double-blind randomized controlled trial. J Clin Pharm Ther. 2001;26(5):369-73.

14. Hosseinzadeh H, Lary P. Effect of Salvia leriifolia leaf extract on morphine dependence in mice. Phytother Res. 2000;14(5):384-7.

15. Ramezani M, Hosseinzadeh H, Mojtahedi K. Effects of Ferula gummosa Boiss. fractions on morphine dependence in mice. J Ethnopharmacol. 2001;77(1):71-5.

16. Abbasi Maleki F, Abbasi Maleki S, Mousavi SZ, Khayatnouri MH, Najafi GH. Effect of hydroalcoholic extract of Avena sativa L. on morphine withdrawal signs in male mice. J Sabzevar Univ Med Sci. 2014;20(4):408-415.

17. Abbasi Maleki N, Abbasi Maleki S, Bekhradi R. Suppressive effects of rosa damascena essential oil on naloxoneprecipitated morphine withdrawal signs in male mice. Iran J Pharm Res. 2013;12(3):357-61.

18. Sadighi S, Abbasi Maleki S, Moradi Kor N. Evaluation of the effect of Origanum majorana L. essential oil on morphine withdrawal signs in male mice. 1st International Conference on Medicine, Public Health and Biological Sciences (MPHBS); Tehran, Iran; 2016:222.

19. Shirzadi D, Abbasi Maleki S, Zanbouri A. Ethanolic extract of anise (Pimpinella anisum L.) attenuates morphine physical dependence in mice. J HerbMed Pharmacol. 2017;6(2):69-73.

20. Salehi Surmaghi MH. Medicinal Plants and Phythotherapy. 3rd ed. Donyayeh Taghzieh Pub; 2000:319-24.

21. Hajhashemi V, Klooshani V. Antinociceptive and antiinflammatory effects of Urtica dioica leaf extract in animal models. Avicenna J Phytomed. 2013;3(2):193-200.

22. Lorke D. A new approach to practical acute toxicity testing. Arch Toxicol. 1983;54(4):275-87.

23. Washton AM, Resnick RB. Clonidine in opiate withdrawal: review and appraisal of clinical findings. Pharmacotherapy. 1981;1(2):140-6.

24. Ghannadi A, Hajhashemi V, Abrishami R. Effects of the Persian Carum copticum fruit extracts on morphine withdrawal syndrome in mice. Res Pharm Sci. 2012;7(3):127-31.

25. Hajhashemi V, Rabbani M, Asghari G, Karami-Saravi Z. Effects of Otostegia persica (Burm.) Boiss on morphine withdrawal syndrome in mice. Iran $\mathrm{J}$ Pharm Res. 2010;3(3):171-5.

26. Eriator II. Naloxone: acute opioid withdrawal syndrome or side effects? Anesth Analg. 1998;87(5):1214. doi: 10.1213/00000539-199811000-00056

27. Williams JT, Christie MJ, Manzoni O. Cellular and synaptic adaptations mediating opioid dependence. Physiol Rev. 2001;81(1):299-343. doi: 10.1152/physrev.2001.81.1.299.

28. Monfared M, Kamkar A, Ghaffari Khaligh S, Jebelli Javan A, Asadi F, Akhundzadeh Basti A. Antioxidative effects of Iranian Urtica dioica L. extracts on the oxidation of sunflower oil. J Med Plant Res. 2011;5(18):4438-45.

29. Baradaran A, Rabiei Z, Rafieian M, Shirzad H. A review study on medicinal plants affecting amnesia through cholinergic system. J HerbMed Pharmacol. 2012;1(1):3-9.

30. Bourgeois C, Leclerc EA, Corbin C, Doussot J, Serrano V, Vanier JR, et al. Nettle (Urtica dioica L.) as a source of antioxidant and anti-aging phytochemicals for cosmetic applications. C R Chim. 2016;19(9):1090-100. doi: 10.1016/j.crci.2016.03.019.

31. Naidu PS, Singh A, Joshi D, Kulkarni SK. Possible mechanisms of action in quercetin reversal of morphine tolerance and dependence. Addict Biol. 2003;8(3):327-36. doi: $\quad 10.1080 / 13556210310001602248$.

32. Salarinia Z, Eidi A, Zarringhalam J. Effects of Bonium persicum B. Fedtsch fruit ethanolic extract on morphine tolerance and dependence in adult male NMRI mice. Med Sci. 2015;25(3):190-7.

33. Colla AR, Oliveira A, Pazini FL, Rosa JM, Manosso LM, Cunha MP, et al. Serotonergic and noradrenergic systems are implicated in the antidepressant-like effect of ursolic acid in mice. Pharmacol Biochem Behav. 2014;124:108-16. doi: $10.1016 /$ j.pbb.2014.05.015.

34. Verano J, Gonzalez-Trujano ME, Deciga-Campos M, Ventura-Martinez R, Pellicer F. Ursolic acid from Agastache mexicana aerial parts produces antinociceptive activity involving TRPV1 receptors, cGMP and a serotonergic synergism. Pharmacol Biochem Behav. 2013;110:255-64. doi: $\quad 10.1016 /$ j.pbb.2013.07.020.

35. Li L, Zhang X, Cui L, Wang L, Liu H, Ji H, et al. Ursolic acid promotes the neuroprotection by activating Nrf2 pathway after cerebral ischemia in mice. Brain Res. 2013;1497:32-9. doi: 10.1016/j.brainres.2012.12.032.

36. Taviano MF, Miceli N, Monforte MT, Tzakou O, Galati EM. Ursolic acid plays a role in Nepeta sibthorpii Bentham CNS depressing effects. Phytother Res. 2007;21(4):382-5. doi: $10.1002 /$ ptr.2076. 